26(3), 471-481

\title{
An One-factor VaR Model for Stock Portfolio
}

\author{
Keunhui $\operatorname{Park}^{a} \cdot$ Kwangyee Ko ${ }^{a, 1} \cdot$ Jangsun Beak $^{a}$ \\ ${ }^{a}$ Department of Statistics, Chonnam National University
}

(Received March 29, 2013; Revised June 10, 2013; Accepted June 11, 2013)

\begin{abstract}
The current VaR Model based on J. P. Morgan's RiskMetrics has problem that actual loss exceeds VaR under unstable economic conditions because the current VaR Model can't reflect future economic conditions. In general, any corporation's stock price is determined by the firm's idiosyncratic factor as well as the common systematic factor that influences all stocks in the portfolio. In this study, we propose an One-factor VaR Model for stock portfolio which is decomposed into the common systematic factor and the firm's idiosyncratic factor. We expect that the actual loss will not exceed VaR when the One-factor Model is implemented because the common systematic factor considering the future economic conditions is estimated. Also, we can allocate the stock portfolio to minimize the loss.
\end{abstract}

Keywords: Generalized Wiener stochastic process, continuously-compounded return, One-factor Model, VaR, EWMA, GARCH.

\section{1. 서론}

시장위험을 관리하기 위한 $\operatorname{VaR}($ Value at Risk) 기법은 1994년에 J. P. Morgan에서 RiskMetrics 모형에서 소개된 이후에 BIS 협약에서 국제적 기준으로 VaR에 근거한 내부모형법(internal model approach)을 이용하여 소요자기자본을 산출할 것을 권고함에 따라 그의 중요성이 더욱 증가되었다. $\mathrm{VaR}$ 은 정상적인 시장상황 하에서 목표보유기간(target horizon) 동안 금리, 주가 및 환율이 불리한 방향으로 변동하여 기초자산의 가격이 특정한 신뢰수준의 범위를 벗어나 발생하는 최대손실을 의미한 다. 그러나 J. P. Morgan의 RiskMetrics을 기반으로 하는 현행 VaR 모형은 몇 가지 문제점을 내포 하고 있다. 첫째 J. P. Morgan의 RiskMetrics 모형은 원래 1일 동안 가격변동에 따른 리스크(DEAR; daily earnings at risk)를 측정하는 것을 목표로 개발하였으나, BIS 자기자본규제에서는 보수성 원칙 에 따라 보유기간을 최소 10 일을 요구하고 있다. 따라서 리스크의 변화를 사전에 인식하더라도 짧은 목표보유기간 내에 보유하고 있는 해당 자산의 포지션을 공정한 가격으로 처분하기가 곤란하다. 둘째 CAPM(Capital Asset Pricing Model) 이론에 따라 주식의 수를 증가하여 포트폴리오를 잘 분산하게 되면 기업의 고유요인에 의해 발생하는 비체계적위험(nonsystematic risk)은 사라지고 단지 경기변동요 인인 체계적위험(systematic risk)만 존재하는 것으로 알려져 있지만, 단지 주식의 수를 증가시키는 방

This research was supported by the National Research Foundation of Korea Grant funded by the Korean Government(2010-0023279).

${ }^{1}$ Corresponding author: Professor, Department of Statistics, Chonnam National University, 77 Yongbong-ro, Buk-gu, Gwangju 500-757, Korea. E-mail: kyko0328@jnu.ac.kr 
법 이외에 포트폴리오 분산을 최소화하는 효율적인 자산구성이 곤란하다. 셋째 현행 VaR 모형에 대한 가장 많은 비판 대상으로 수익률의 분포를 정규분포로 가정하여 리스크를 과소추정하는 경향이 있다는 것이다 (Neftci, 2000). 특히 주식의 수가 적고 포트폴리오 분산이 잘 이루어지지 않은 경우에는 과소추 정 경향이 더욱 심하다 (Johansson 등, 1999).

기업의 미래의 주가는 해당 기업만의 고유요인은 물론 모든 기업의 주가에 공통적으로 영향을 미치는 경 기변동 공통요인에 의해 결정된다. 본 연구에서는 주가의 변동요인을 기업의 고유요인과 경기변동 공 통요인으로 구분하여, 미래 경기변동 공통요인에 대해서는 현재 시점에서 예측한 값을 사용하는 원-팩 터(One-factor) VaR 모형을 제안한다. 주가의 변동요인을 기업의 고유요인과 경기변동 공통요인으로 별도로 구분하지 않는 현행 $\mathrm{VaR}$ 모형은 비록 미래의 경기상황을 예측한 경우라 할지라도 구조적으로 예측된 경기상황을 반영할 수가 없다. 목표보유기간이 길어질수록 변동성이 증가하여 과도한 리스크를 산출하기 때문에 목표보유기간을 짧게 정한 가장 큰 이유이겠지만, 목표보유기간이 짧은 경우에는 보유 기간 동안 경기상황은 현재 경기상황과 유사할 것이므로 미래 경기상황을 예측할 필요성이 없는 $\mathrm{VaR}$ 모형을 정당화할 수도 있다. 주가의 변동성인 안정적인 정상시장 여건 하에서는 $\mathrm{VaR}$ 을 초과하는 손실 사례가 거의 발생하지 않지만, 주로 주가의 변동성이 불안정한 시장상황에서는 손실금액이 $\mathrm{VaR}$ 을 초과 하는 사례가 발생한다. 따라서 리스크를 과소추정하는 근본적인 이유가 정규성 가정보다는 미래 경기상 황을 반영하지 않아서 발생하는 문제로 판단된다. 본 연구에서 제안하는 원-팩터 $\mathrm{VaR}$ 모형에서는 현행 $\mathrm{VaR}$ 모형과 동일하게 정규성을 가정한다. 그러나 주어진 평균값에 대해 분포의 중심위치가 변하지 않 고 변동성에 의존하여 리스크량을 결정하는 현행 $\mathrm{VaR}$ 모형과는 달리 원-팩터 $\mathrm{VaR}$ 모형은 추정된 변동 성에 대해 미래 예측되는 경기상황에 따라 분포의 중심위치가 이동한다. 따라서 미래 경기상황이 악화 되어질 것으로 예상되는 경우에는 분포의 중심위치가 해당 경기상황으로 이동하므로 현행 $\mathrm{VaR}$ 모형에 비해 $\mathrm{VaR}$ 을 초과하는 손실 사례에 대한 문제점을 개선할 수 있을 것으로 판단된다. 또한 원-팩터 $\mathrm{VaR}$ 모형에서는 각 기업의 주가를 가장 잘 설명하는 경기지표로 경기변동요인을 선택하기 때문에 선택되어 진 경기지표에 따라 포트폴리오를 구성하는 전체 주식을 몇 개의 그룹으로 분류할 수가 있다. 따라서 선 택되어진 경기지표 중에서 현재 경기상황에 비해 악화가 예상되는 경기지표에 해당하는 그릅의 주식들 은 투자금액을 감소하고, 반대로 현재 경기상황에 비해 호전되어질 것으로 예상되는 경기지표에 해당하 는 그룹의 주식들은 투자금액을 증가하는 방법으로 포트폴리오의 자산구성은 물론 자금이전을 효율적으 로 실시할 수 있다.

지금까지 $\mathrm{VaR}$ 에 관한 연구는 주로 수익률이 자기상관성(autocorrelation)이 존재하는 시계열 자료의 특성을 고려하여 주로 수익률의 이분산성(heteroscedasticity)을 추정하는 방법에 집중하여, 단순이동평 균법(simple moving average model)을 대체할 수 있는 EWMA(exponential weighted moving average model), ARCH(autoregressive conditional heteroscedasticity), 및 GARCH(generalized autoregressive conditional heteroscedasticity) 등과 같은 이론적 발전을 이루었다. 이와 같은 이론적 성과를 기 반으로 본 연구에서 제안하는 원-팩터 $\mathrm{VaR}$ 모형은 구조적으로 미래 예상되는 경기상황을 반영함으로써 현행 $\mathrm{VaR}$ 모형에 대한 근본적인 문제점을 개선하고자 한다.

\section{2. 원-팩터 $\mathrm{VaR}$ 모형}

\section{1. 원-팩터 $\operatorname{VaR}$ 모형}

어느 주가 수익률의 평균이 $\mu$ 이고 변동성이 $\sigma$ 인 $t$ 시점의 주가 $S(t)$ 은 무한히 작은 시간증분 $d t$ 에 따 른 주가 $S(t+d t)$ 에 대한 주가의 이산수익률이 다음과 같은 일반화 위너확률과정 (generalized Wiener 
stochastic process)을 따르는 것으로 가정하자.

$$
\frac{d S(t)}{S(t)}=\mu d t+\sigma d W(t)
$$

여기서 $d W(t)$ 은 위너과정(Wiener process)의 조건을 만족하는 확률변수로서 시간증분 $d t$ 에 따라 정 규분포 $N(0, d t)$ 을 따르는 것으로 가정한다. 만일 일반화 위너확률과정을 따르는 $S(t)$ 을 로그주가 $\ln S(t)$ 로 변환하면, 식 (2.1)은 이토정리에 의해 다음과 같은 확률미분방정식으로 유도된다.

$$
d \ln S(t)=\left(\mu-\frac{\sigma^{2}}{2}\right) d t+\sigma d W(t)
$$

이와 같은 결과에 의해, 현재 $t$ 시점의 주가 $S(t)$ 에 대해서 미래 $T$ 시점의 주가 $S(T)$ 에 관한 확률모형은 다음과 같다.

$$
S(T)=S(t) \exp \left\{\left(\mu-\frac{\sigma^{2}}{2}\right)(T-t)+\sigma W(T)\right\} .
$$

이 때, 위너과정을 따르는 확률변수 $W(T)$ 은 정규분포 $N(0,(T-t))$ 을 따르므로 표준정규분포를 따르 는 확률변수 $Z(T)$ 에 의해 미래 $T$ 시점의 주가 $S(T)$ 에 관한 확률모형을 다음과 같이 표현하기로 하자.

$$
S(T)=S(t) \exp \left\{\left(\mu-\frac{\sigma^{2}}{2}\right)(T-t)+\sigma \sqrt{T-t} Z(T)\right\} .
$$

어느 기업의 미래 $T$ 시점의 주가 $S(T)$ 은 기업의 내부 고유요인은 물론 경기변동과 같은 외부요인에 의 해 결정된다. 따라서 위너과정을 만족하는 확률변수 $Z(T)$ 을 모든 기업의 주가에 공통적으로 영향을 미치는 경기변동 공통요인(systematic factor) $X(T)$ 와 해당 기업만의 고유요인(idiosyncratic factor) $Y(T)$ 으로 구분한 다음과 같은 원-팩터(One-factor) 모형을 고려하기로 하자.

$$
Z(T)=\sqrt{\rho} X(T)+\sqrt{1-\rho} Y(T),
$$

여기서 $\rho$ 는 주가 $S(T)$ 에 대한 공통요인 $X(T)$ 의 영향력을 의미한다. 공통요인 $X(T)$ 와 고유요인 $Y(T)$ 은 서로 독립이고 각각 표준정규분포를 따른다. 또한 기업간 기업의 고유요인 $Y(T)$ 은 서로 독 립이지만, 경기변동 공통요인은 $Y(T)$ 은 서로 영향을 미치는 확률변수이다. 그러면 현재 $t$ 시점의 주가 $S(t)$ 에 대해서 미래 $T$ 시점의 주가 $S(T)$ 에 관한 원-팩터 모형은 다음과 같이 정의된다.

$$
S(T)=S(t) \exp \left\{\left(\mu-\frac{\sigma^{2}}{2}\right)(T-t)+\sigma \sqrt{T-t}(\sqrt{\rho} X(T)+\sqrt{1-\rho} Y(T))\right\} .
$$

이 때, 로그주가 $\ln S(T)$ 은 정규분포를 따르므로 주가 $S(T)$ 에 관한 원-팩터 모형은 로그정규분포를 따 른다. 모든 기업에 대해서 해당 기업만의 고유요인 $Y(T)$ 을 예측한다는 것은 어려운 일이지만, 일반적 으로 모든 기업의 주가에 공통적으로 영향을 미치는 경제성장률이나 소비자물가지수와 같은 경기변동 공통요인 $X(T)$ 은 여러 가지 경제적 상황을 고려하여 예측을 실시한다. 따라서 본 연구에서는 선제적인 리스크 측정을 위해서 현재 $t$ 시점에서 미래 $T$ 시점의 경기변동 공통요인 $X(T)$ 에 대한 예측값이 $x$ 로 주 어진 것으로 가정한다. 그러면 현재 $t$ 시점에서 미래 $T$ 시점의 $X(T)$ 에 대한 예측값이 $x$ 로 주어진 조건 하에서, 본 연구에서 제안하는 미래 $T$ 시점의 주가 $S(T)$ 에 관한 원-팩터 모형은 다음과 같다.

$$
S(T)=S(t) \exp \left\{\left(\mu-\frac{\sigma^{2}}{2}\right)(T-t)+\sigma \sqrt{T-t}(\sqrt{\rho} x+\sqrt{1-\rho} Y(T))\right\} .
$$


이와 같은 로그정규분포를 따르는 원-팩터 모형으로부터 미래 $T$ 시점의 주가 $S(T)$ 에 대한 기댓값 $E[S(T)]$ 로부터 주가가 어느 임계값 $S_{\alpha}(T)$ 으로 하락하여 발생한 손실을 $\mathrm{VaR}$ 로 정의하자.

$$
\operatorname{VaR}=E[S(T)]-S_{\alpha}(T),
$$

여기서 임계값 $S_{\alpha}(T)$ 은 로그정규분포로부터 신뢰수준 $\alpha$ 에 대해 확률 $1-\alpha$ 을 만족한다.

$$
1-\alpha=P\left(S(T) \leq S_{\alpha}(T) \mid X(T)=x\right) .
$$

식 (2.2)의 미래 $T$ 시점의 주가 $S(T)$ 에 관한 원-팩터 모형에서 기업의 고유요인인 확률변수 $Y(T)$ 은 표 준정규분포를 따르므로 현재 $t$ 시점의 주가 $S(t)$ 에 대한 미래 $T$ 시점의 주가 $S(T)$ 의 로그수익률(또는 연 속수익률 $) r(T)$ 은 정규분포를 따른다.

$$
r(T)=\ln \frac{S(T)}{S(t)}=\left(\mu-\frac{\sigma^{2}}{2}\right)(T-t)+\sigma \sqrt{T-t}(\sqrt{\rho} x+\sqrt{1-\rho} Y(T)) .
$$

따라서 $\mathrm{VaR}$ 을 계산하기 위해 로그정규분포로부터 미래 $T$ 시점의 주가 $S(T)$ 에 대한 기댓값 $E[S(T)]$ 과 임계값 $S_{\alpha}(T)$ 을 직접 유도하지 않고, 정규분포를 따르는 로그수익률 $r(T)$ 의 분포로부터 간접적으로 유 도한다. 즉 다음과 같은 로그수익률 $r(T)$ 에 대한 기댓값으로부터

$$
E[r(T)]=\left(\mu-\frac{\sigma^{2}}{2}\right)(T-t)+\sigma \sqrt{T-t} \sqrt{\rho} x .
$$

미래 $T$ 시점의 주가 $S(T)$ 에 대한 기댓값은 다음과 같이 유도된다.

$$
E[S(T)]=S(t) e^{E[r(T)]}=S(t) \exp \left[\left(\mu-\frac{\sigma^{2}}{2}\right)(T-t)+\sigma \sqrt{T-t} \sqrt{\rho} x\right] .
$$

또한 만일 표준정규분포를 따르는 확률변수 $Y(T)$ 에 대하여 확률 $1-\alpha$ 을 만족하는 임계값을 $y_{\alpha}$ 라 하면

$$
1-\alpha=P\left(Y(T) \leq y_{\alpha}\right) .
$$

정규분포를 따르는 로그수익률 $r(T)$ 의 분포로부터 신뢰수준 $\alpha$ 에 대한 확률 $1-\alpha$ 을 만족하는 임계값 $r_{\alpha}$ 은 다음과 같다.

$$
r_{\alpha}=\left(\mu-\frac{\sigma^{2}}{2}\right)(T-t)+\sigma \sqrt{T-t}\left(\sqrt{\rho} x+\sqrt{1-\rho} y_{\alpha}\right) .
$$

따라서 로그정규분포로부터 신뢰수준 $\alpha$ 에 대해서 확률 $1-\alpha$ 을 만족하는 임계값 $S_{\alpha}(T)$ 은 다음과 같이 유도된다.

$$
S_{\alpha}(T)=S(t) e^{r_{\alpha}}=S(t) \exp \left[\left(\mu-\frac{\sigma^{2}}{2}\right)(T-t)+\sigma \sqrt{T-t}\left(\sqrt{\rho} x+\sqrt{1-\rho} y_{\alpha}\right)\right] .
$$

현재 $t$ 시점에서 미래 $T$ 시점의 경기변동 공통요인 $X(T)$ 에 대한 예측값이 $x$ 로 주어진 조건 하에서, 본 연구에서 제안하는 신뢰수준 $\alpha$ 에 대한 원-팩터 $\mathrm{VaR}$ 은 다음과 같이 정의된다.

$$
\begin{aligned}
& \mathrm{VaR}=E[S(T)]-S_{\alpha}(T) \\
& =S(t) e^{\mu(T-t)+\sigma \sqrt{T-t} \sqrt{\rho} x}-S(t) e^{r_{\alpha}} \\
& =S(t) e^{\mu(T-t)+\sigma \sqrt{T-t} \sqrt{\rho} x}\left(1-e^{\sigma \sqrt{T-t} \sqrt{1-\rho}} y_{\alpha}\right) .
\end{aligned}
$$




\section{2. 주식 포트폴리오 원-팩터 $\mathrm{VaR}$ 모형}

어느 $n$ 개 주식에 대해 각각의 주식의 주가변동을 가장 잘 설명하는 경기변동 공통요인이 $l$ 개가 선택 되었다고 가정하고, $n$ 개 주식을 선택된 $l$ 개의 경기변동 공통요인에 따라 분류한 각 그룹의 주식 수를 $n_{1}, n_{2}, \ldots, n_{l}$ 라 하자. 또한 현재 $t$ 시점에서 전체 $n$ 개 주식 포트폴리오에 대한 총투자금액을 $P(t)$ 라 하 고, $k$ 그룹 내의 어느 주식 $i$ 에 대한 투자금액을 $P_{i}^{(k)}(t)$ 라 하자. 그러면 $k$ 그룹 내의 주식 $i$ 에 대한 투자 비율 $w_{i}^{(k)}$ 은 다음과 같다.

$$
w_{i}^{(k)}=\frac{P_{i}^{(k)}(t)}{P(t)} .
$$

따라서 현재 $t$ 시점에서 총투자금액 $P(t)$ 을 $n$ 개 주식에 분산투자한 포트폴리오를 투자비율에 의해 다음 과 같이 나타낼 수 있다.

$$
P(t)=\sum_{k=1}^{l} \sum_{i=1}^{n_{l}} P_{i}^{(k)}(t)=\sum_{k=1}^{l} \sum_{i=1}^{n_{l}} P(t) w_{i}^{(k)} .
$$

이 때, 전체 $n$ 개 주식에 대한 투자비율의 합은 1 을 만족한다.

$$
\sum_{k=1}^{l} \sum_{i=1}^{n_{l}} w_{i}^{(k)}=1
$$

따라서 어느 $t$ 시점 총투자금액 $P(t)$ 에 대해 무한히 작은 시간증분 $d t$ 에 따른 $P_{p}(t+d t)$ 을 $k$ 그룹에 속하 는 $n$ 개 주식포트폴리오로 다음과 같이 표현할 수 있다.

$$
\begin{aligned}
P(t+d t) & =\sum_{k=1}^{l} \sum_{i=1}^{n_{l}} P(t+d t) w_{i}^{(k)} \\
& =\sum_{k=1}^{l} \sum_{i=1}^{n_{l}} P(t) w_{i}^{(k)} \frac{P(t+d t) w_{i}^{(k)}}{P(t) w_{i}^{(k)}} \\
& =\sum_{k=1}^{l} \sum_{i=1}^{n_{l}} P(t) w_{i}^{(k)}\left(1+\frac{P(t+d t) w_{i}^{(k)}-P(t) w_{i}^{(k)}}{P(t) w_{i}^{(k)}}\right) \\
& =\sum_{k=1}^{l} \sum_{i=1}^{n_{l}} P(t) w_{i}^{(k)}+\sum_{k=1}^{l} \sum_{i=1}^{n_{l}} P(t) w_{i}^{(k)} \frac{P(t+d t) w_{i}^{(k)}-P(t) w_{i}^{(k)}}{P(t) w_{i}^{(k)}} \\
& =P(t)+\sum_{k=1}^{l} \sum_{i=1}^{n_{l}} P(t) w_{i}^{(k)} \frac{P(t+d t) w_{i}^{(k)}-P(t) w_{i}^{(k)}}{P(t) w_{i}^{(k)}} .
\end{aligned}
$$

만일 $k$ 그룹 내의 어느 주식 $i$ 에 대한 수익률의 평균과 표준편차가 각각 $\mu_{i}^{(k)}$ 와 $\sigma_{i}^{(k)}$ 인 $t$ 시점의 투자금액 $P_{i}^{(k)}(t)$ 은 무한히 작은 시간증분 $d t$ 에 따라 일반화 위너과정을 따른다고 하자.

$$
\frac{d P_{i}^{(k)}(t)}{P_{i}^{(k)}(t)}=\mu_{i}^{(k)} d t+\sigma_{i}^{(k)} d W_{i}^{(k)}(t) .
$$

그러면 식 $(2.3)$ 으로부터 총투자금액 $P(t)$ 에 대한 시간증분 $d t$ 에 따른 일반화 확률과정은 전체 $n$ 개 주 식에 대한 일반화 확률과정의 가중 합으로 다음과 같이 표현할 수 있다.

$$
\frac{d P(t)}{P(t)}=\frac{P(t+d t)-P(t)}{P(t)}
$$




$$
\begin{aligned}
& =\sum_{k=1}^{l} \sum_{i=1}^{n_{l}} w_{i}^{(k)} \frac{P(t+d t) w_{i}^{(k)}-P(t) w_{i}^{(k)}}{P(t) w_{i}^{(k)}} \\
& =\sum_{k=1}^{l} \sum_{i=1}^{n_{l}} w_{i}^{(k)} \frac{P_{i}^{(k)}(t+d t)-P_{i}^{(k)}(t)}{P_{i}^{(k)}(t)} \\
& =\sum_{k=1}^{l} \sum_{i=1}^{n_{l}} w_{i}^{(k)} \frac{d P_{i}^{(k)}(t)}{P_{i}^{(k)}(t)} \\
& =\sum_{k=1}^{l} \sum_{i=1}^{n_{l}} w_{i}^{(k)}\left(\mu_{i}^{(k)} d t+\sigma_{i}^{(k)} d W_{i}^{(k)}(t)\right) .
\end{aligned}
$$

또한 이토정리에 의하여, $t$ 시점 총투자금액 $P(t)$ 에 대해 시간증분 $d t$ 에 따른 로그수익률 $d \ln P(t)$ 은 전 체 $n$ 개 주식에 대한 로그수익률 $\ln P_{i}^{(k)}(t)$ 의 가중 합이다.

$$
d \ln P(t)=\sum_{k=1}^{l} \sum_{i=1}^{n_{l}} w_{i}^{(k)}\left(\left(\mu_{i}^{(k)}-\frac{\left(\sigma_{i}^{(k)}\right)^{2}}{2}\right) d t+\sigma_{i}^{(k)} d W_{i}^{(k)}(t)\right) .
$$

만일 어느 $k$ 그룹의 경기변동요인 $X_{k}(T)$ 에 대해 주식 $i$ 의 영향력을 $\rho_{i}^{(k)}$ 라 하고, 또한 현재 $t$ 시점에서 $l$ 개 그룹에 대한 미래 $T$ 시점의 경기변동요인이 $x_{1}, x_{2}, \ldots, x_{l}$ 로 예측되어진 경우에는 현재 $t$ 시점의 총투 자금액 $P(t)$ 에 대해서 미래 $T$ 시점의 주식포트폴리오 $P(T)$ 에 관한 원-팩터 모형은 다음과 같다.

$$
P(T)=P(t) e^{r_{p}(T)},
$$

여기서 $r_{p}(T)$ 은 현재 $t$ 시점의 총투자금액 $P(t)$ 에 대한 미래 $T$ 시점의 주식포트폴리오 $P(T)$ 의 로그수익 률로서 정규분포를 따른다.

$r_{p}(T)=\sum_{k=1}^{l} \sum_{i=1}^{n_{l}} w_{i}^{(k)}\left[\left(\mu_{i}^{(k)}-\frac{\left(\sigma_{i}^{(k)}\right)^{2}}{2}\right)(T-t)+\sigma_{i}^{(k)} \sqrt{T-t}\left(\sqrt{\rho_{i}^{(k)}} x_{k}+\sqrt{1-\rho_{i}^{(k)}} Y_{i}^{(k)}(T)\right)\right]$.

현행 $\operatorname{VaR}$ 모형에서는 주식의 수가 $n$ 인 경우 $n(n-1) / 2$ 개의 상관관계를 추정하여야 하는 부담이 있 다. 그러나 본 연구에서는 $l$ 개 그룹에 대한 미래 $T$ 시점의 경기변동요인 $X_{1}(T), X_{2}(T), \ldots, X_{l}(T)$ 이 서 로 상관관계가 존재하지만, 미래의 경기상황을 선제적으로 반영하기 위해 예측값 $x_{1}, x_{2}, \ldots, x_{l}$ 으로 고 정된 상태이므로 상관관계를 고려할 필요가 없다는 부가적인 장점도 가진다. 따라서 $n$ 개의 개별 주식의 고유요인들은 서로 독립적인 표준정규분포를 따르므로 주식포트폴리오 로그수익률 $r_{p}(T)$ 에 대한 기댓 값 $E\left[r_{p}(T)\right]$ 은 다음과 같으며

$$
E\left[r_{p}(T)\right]=\sum_{k=1}^{l} \sum_{i=1}^{n_{l}} w_{i}^{(k)}\left[\left(\mu_{i}^{(k)}-\frac{\left(\sigma_{i}^{(k)}\right)^{2}}{2}\right)(T-t)+\sigma_{i}^{(k)} \sqrt{T-t} \sqrt{\rho_{i}^{(k)}} x_{k}\right] .
$$

또한 로그수익률 $r_{p}(T)$ 에 대한 분산 $\operatorname{Var}\left[r_{p}(T)\right]$ 은 다음과 같이 공분산이 존재하지 않는다.

$$
\operatorname{Var}\left[r_{p}(T)\right]=\sum_{k=1}^{l} \sum_{i=1}^{n_{l}}\left(w_{i}^{(k)}\right)^{2}\left(\sigma_{i}^{(k)}\right)^{2}(T-t)\left(1-\rho_{i}^{(k)}\right) .
$$

따라서 기댓값 $E\left[r_{p}(T)\right]$ 을 이용하여, 로그정규분포를 따르는 미래 $T$ 시점의 주식포트폴리오 $P(T)$ 에 대 한 기댓값은 다음과 같이 주어진다.

$$
E[P(T)]=P(t) e^{E\left[r_{p}(T)\right]} .
$$


또한 신뢰수준 $\alpha$ 에 대해 표준정규분포로부터 확률 $1-\alpha$ 을 만족하는 개별 주식의 고유요인 $Y_{i}^{(k)}(T)$ 에 대한 임계값을 $y_{\alpha}$ 하면

$$
1-\alpha=P\left(Y_{i}^{(k)}(T) \leq y_{i}^{(k)}(\alpha)\right)
$$

확률 $1-\alpha$ 을 만족하는 로그수익률 $r_{p}(T)$ 의 임계값 $r_{p}(\alpha)$ 은 다음과 같이 주어진다.

$$
r_{p}(\alpha)=\sum_{k=1}^{l} \sum_{i=1}^{n_{l}} w_{i}^{(k)}\left[\left(\mu_{i}^{(k)}-\frac{\left(\sigma_{i}^{(k)}\right)^{2}}{2}\right)(T-t)+\sigma_{i}^{(k)} \sqrt{T-t}\left(\sqrt{\rho_{i}^{(k)}} x_{k}+\sqrt{1-\rho_{i}^{(k)}} y_{i}^{(k)}(\alpha)\right)\right] .
$$

따라서 로그정규분포로부터 확률 $1-\alpha$ 을 만족하는 미래 $T$ 시점의 주식포트폴리오 $P(T)$ 의 임계값 $P(\alpha)$ 은 다음과 같이 유도된다.

$$
P(\alpha)=P(t) e^{r_{p}(\alpha)}
$$

현재 $t$ 시점에서 $l$ 개 그룹에 대한 미래 $T$ 시점의 경기변동요인이 예측값 $x_{1}, x_{2}, \ldots, x_{l}$ 로 주어진 상태에 서, 본 연구에서 제안하는 미래 $T$ 시점의 원-팩터 포트폴리오 $P(T)$ 에 대한 신뢰수준 $\alpha$ 의 $\operatorname{VaR}$ 은 다음과 같이 주어진다.

$$
\begin{aligned}
\operatorname{VaR}_{p} & =E[P(T)]-P(\alpha) \\
& =P(t)\left(e^{E\left[r_{p}(T)\right]}-e^{r_{p}(\alpha)}\right) .
\end{aligned}
$$

\section{3. 실증분석}

일반적으로 주식의 수익률은 시계열 특성으로 서로 독립적이지 않고 최근의 수익률에 대해서 영향을 많 이 받고 시점이 멀어짐에 따라 의존도가 점차 감소한다. 따라서 현재 $t$ 시점에서 어느 주식에 대한 미래 $t+1$ 시점의 이산수익률을 $\tau(t+1)$ 이라고 하면

$$
\tau(t+1)=\frac{S(t+1)-S(t)}{S(t)} .
$$

이산수익률 $\tau(t+1)$ 은 시점이 멀어짐에 따라 의존도가 점차 감소하여 0 시점 이전에는 영향을 받지 않고 0 시점 이후의 $\tau(0), \tau(1), \tau(2), \ldots, \tau(t)$ 에 영향을 받는 것으로 가정하자. 이러한 주식 수익률 자료의 시 계열 특성을 고려하여 미래 $t+1$ 시점의 이산수익률 $\tau(t+1)$ 에 대한 분산 $\sigma_{t+1}^{2}$ 의 추정방법을 고려하자. 먼저 지수가중이동평균법(EWMA; exponentially weighted moving average)은 현재 $t$ 시점에서 분산의 추정치가 $\hat{\sigma}_{t}^{2}$ 으로 알려진 경우 이산수익률 $\tau(t+1)$ 의 분산 추정치 $\hat{\sigma}_{t+1}^{2}$ 은 다음과 같이 0 과 1 사이의 소 멸계수(decay factor) $\lambda$ 에 대해 직전 분산의 추정치 $\hat{\sigma}_{t}^{2}$ 에 $\lambda$ 만큼 의존하고 현재 $t$ 시점의 분산 $\tau(t)^{2}$ 에는 $(1-\lambda)$ 만큼 의존한다.

$$
\hat{\sigma}_{t+1}^{2}=\lambda \hat{\sigma}_{t}^{2}+(1-\lambda) \tau(t)^{2},
$$

여기서 이산수익률의 평균은 0 으로 가정하였으며, 만일 0 시점까지 확장하면 다음과 같이 시점이 멀어질 수록 $i$ 가 증가하여 가중치가 작아지는 결과가 유도된다.

$$
\hat{\sigma}_{t+1}^{2}=(1-\lambda) \sum_{i=1}^{t} \lambda^{i-1} \tau(i)^{2}+\lambda^{t} \hat{\sigma}_{0}^{2}
$$


또한 Eagle (1982)에 의해 처음으로 제시된 $\mathrm{ARCH}(t)$ 모형은 장기평균분산 $V_{L}$ 에 $\gamma$ 만큼 가중치를 부여 하고, $i$ 일 이전의 수익률 분산 $\tau(t-i)^{2}$ 에는 가중치 $\alpha_{i}$ 을 부여하는 방법이다.

$$
\hat{\sigma}_{t+1}^{2}=\gamma V_{L}+\sum_{i=1}^{t} \alpha_{i} \tau(t-i)^{2},
$$

여기서 가중치 합은 $\gamma+\sum_{i=1}^{t} \alpha_{i}=1$ 을 만족한다. 그리고 최근의 $\operatorname{Bollerslev~(1986)ㅇㅔ~ㅇㅢㅎㅏㄴ~} \operatorname{GARCH}(1,1)$ 모형은 $\operatorname{ARCH}(t)$ 모형을 일반화한 형태로서 $\gamma+\alpha+\beta=1$ 을 만족한다.

$$
\hat{\sigma}_{t+1}^{2}=\gamma V_{L}+\alpha \tau(t)^{2}+\beta \hat{\sigma}_{t}^{2} .
$$

EWMA 모형은 $\operatorname{GARCH}(1,1)$ 모형에서 $\gamma=1, \alpha=1, \beta=\lambda$ 인 특수한 형태로써, $\operatorname{GARCH}(1,1)$ 모형 이 이론적으로 매력적인 장점을 갖지만 $\mathrm{EWMA}$ 은 상대적으로 계산이 단순하다는 장점이 있다. 두 방법 에 의한 분산 추정치는 거의 유사한 상태이어서, 본 연구에서는 계산이 단순한 EWMA 모형을 이용하 여 분산 $\sigma_{t+1}^{2}$ 을 추정하였다. 그리고 현행 $\mathrm{VaR}$ 모형에서는 주식의 목표보유기간이 1 일이므로 일별 수 익률의 분산을 추정하나, 본 연구에서는 경기변동에 대한 예측에 따른 선제적인 $\mathrm{VaR}$ 을 추정한다는 점 을 강조하기 위해 주식의 목표보유기간을 1 개월로 결정하여 주식의 월별 평균 수익률에 대한 분산을 추 정하였다. 이 때, 소멸계수 $\lambda$ 은 0.97 을 사용하였다.

미래의 경기상황을 나타내는 공통요인은 예측 가능한 경제지표 이용하여야 한다. 본 연구에서는 2005년 06월 2012년 06월 동안 국가통계포털(www.kosis.kr)에 공시된 각종 경제지표를 공통요인 으로 이용하였다. 원칙적으로 경기변동 공통요인은 주식별로 각각 선택하여야 하나, 본 연구에서는 산 업별 특성을 고려하기 위해 36 의 업체를 표준산업분류코드에 따라 9 개 업종으로 분류한 다음, 각종 경 기지표 중에서 업종별 시가총액주가지수의 수익률에 대한 회귀설명력이 가장 높은 경기지표를 그 산업 의 경기변동 공통요인으로 선택하였다.

$$
f(i \text { 산업 시가총액주가지수 수익률 })=\alpha_{i}+\beta_{i} \times(\text { 표준화 경기변동 공통요인 })+\epsilon_{i} \text {. }
$$

또한 업종 내의 각 주식의 이산수익률에 대한 선택 경기변동 공통요인의 영향력 $\rho$ 은 각 주식의 수익률에 대한 선택된 경기변동 공통요인의 회귀모형에서 결정계수 $R^{2}$ 로 추정하였다.

$$
\rho=R^{2} \text {. }
$$

KOSPI주가지수를 경기순환에 따른 주가변화를 나타내는 대표적인 지표로 선정하여 KOSPI주가지 수에 따른 9 개 업종에 대한 선택된 각 경기변동 경기지표의 변화를 회귀모형으로 도출하였다. 또한 $\mathrm{KOSPI}$ 주가지수를 표준화하여 경기상태를 의미하는 값으로 $2,1,0,-1,-2$ 를 임의적으로 주어진 상태이 며, 회귀모형식에 의해 이 값에 대한 선택된 각 업종의 표준화 경기지표는 다음 Table 3.2 와 같이 주어 진다.

현재 $t$ 시점의 총투자금액 $P(t)$ 에 대해서 미래 $T$ 시점의 주식포트폴리오 $P(T)$ 에 관한 원-팩터 모형과 비 교를 위한 다음과 같은 현행 모형 $P^{*}(T)$ 은 경기변동 공통요인과 기업의 고유요인을 분해하지 않은 형태 이다.

$$
P^{*}(T)=P(0) e^{\left(\mu-\frac{\sigma^{2}}{2}\right)(T-t)+\sigma \sqrt{T-t} Z(T)} .
$$

다음 Table 3.3 에서는 9 개 업종에 속하는 36 개 업체들을 대상으로 현행 모형과 원-팩터 모형에 의한 포 트폴리오 $\operatorname{VaR}_{p}$ 을 비교하였다. 현행 주식포트폴리오 모형은 $n$ 개 기업의 수익률에 대해서 $n(n-1) / 2$ 개 
Table 3.1. Systematic factors by Industry Section

\begin{tabular}{ccc}
\hline Industry & No. of Company & Systematic factor \\
\hline Medicine & 4 & Index of Services \\
Chemistry & 9 & Index of industrial product \\
Steel \& Metal & 2 & Value of construction completed \\
Food & 2 & Index of shipment for domestic market \\
Electric \& Electronic & 6 & Wholesale and retail sales index \\
Construction & 4 & Index of industrial product \\
Electricity \& Gas & 1 & Consumer goods volume index of import \\
Service & 4 & Index of Services \\
Distribution & 4 & Index of industrial product
\end{tabular}

Table 3.2. The observed values of systematic factor for the state of the economy

\begin{tabular}{crrrrr}
\hline Systematic factor & \multicolumn{1}{c}{2} & 1 & 0 & \multicolumn{1}{c}{-1} & -2 \\
\hline Index of Services & 1.526580 & 0.763290 & 0.000000 & -0.763290 & -1.526580 \\
Index of industrial product & 1.745760 & 0.872880 & 0.000000 & -0.872880 & -1.745760 \\
Value of construction completed & -0.983540 & -0.491770 & 0.000000 & 0.491770 & 0.983540 \\
Index of shipment for domestic market & 1.840500 & 0.920250 & 0.000000 & -0.920250 & -1.840500 \\
Wholesale and retail sales index & 1.687460 & 0.843730 & 0.000000 & -0.843730 & -1.687460 \\
Consumer goods volume index of import & 1.703640 & 0.851820 & 0.000000 & -0.851820 & -1.703640 \\
\hline
\end{tabular}

Table 3.3. VaR value of Stock portfolio after a month

\begin{tabular}{cccccc}
\hline $\begin{array}{c}\text { Systematic } \\
\text { factor }\end{array}$ & $E[P(T)]$ & $P(0.95)$ & $\operatorname{VaR}_{p}$ & $\begin{array}{c}\text { Capital Loss } \\
P(t)-E[P(T)]\end{array}$ & $\begin{array}{c}\text { VaR }_{p}+ \\
\text { Capital Loss }\end{array}$ \\
\hline 2 & 101.747 & 97.617 & 4.131 & -1.747 & 2.394 \\
1 & 100.870 & 96.775 & 4.095 & -0.870 & 3.225 \\
0 & 100.000 & 95.940 & 4.060 & 0.000 & 4.060 \\
-1 & 99.138 & 95.113 & 4.025 & 0.862 & 4.887 \\
-2 & 98.283 & 94.292 & 3.990 & 1.717 & 5.708 \\
\hline 현행 모형 & 100.000 & 90.732 & 9.268 & 0.000 & 9.268 \\
\hline
\end{tabular}

의 공분산을 추정하였다. KOSPI주가지수에 대해서 철강업의 경기변동 공통요인인 건설기성액은 음 의 상관관계를 갖지만 나머지 9 개 업종의 경기변동 공통요인은 KOSPI주가지수와 양의 상관관계를 갖 는다. 따라서 업종별 상관관계가 존재하지 않는 원-팩터 모형에 의한 $\mathrm{VaR}_{p}$ 에 비해 현행 모형에 의한 $\mathrm{VaR}_{p}$ 가 크게 나타났다. 또한 미래의 경기상황을 반영할 수 없는 현행 모형과는 달리 원-팩터 모형은 경기상황에 따라 $\mathrm{VaR}_{p}$ 가 서로 다른 값을 나타낸다. 이 때, 원-팩터 모형은 미래 $T$ 시점의 경기상황 이 악화되어지는 경우 포트폴리오의 기대가치 $E[P(T)]$ 는 현재 $t$ 시점의 투자금액 100 보다 작다. 따라 서 원-팩터 모형의 경우 보다 정확한 손실을 예측하기 위해서는 $\mathrm{VaR}_{p}$ 에 대해 경기상황에 따라 자본손 실(capital loss)을 추가적으로 반영하여야 한다.

$$
\text { Capital Loss }=P(t)-E[P(T)] .
$$

\section{4. 결론}

본 연구에서는 구조적으로 예측되는 경기상황과는 관계없이 항상 경기중립적인 현행 $\mathrm{VaR}$ 모형의 단점 을 보완하기 위하여 미래 예측되는 경기상황을 반영할 수 있는 원-팩터 $\mathrm{VaR}$ 모형을 제안하였다. 또한 
원-팩터 $\mathrm{VaR}$ 모형에 의해 미래의 경기상황을 구조적으로 반영할 수 있다는 점만을 강조하기 위해 단지 36 개 상장사를 대상으로 선택 경기지표에 대한 실제 예측치를 사용하지 않고 가상의 예측치의 변화에 따른 포트폴리오 $\mathrm{VaR}$ 의 변화를 실증분석을 통해 살펴보았다. 금융기관의 자산을 구성하는 실제 주식포 트폴리오를 대상으로 경기지표에 대한 예측치 변화에 따른 실제 손실이 원-팩터 모형의 $\mathrm{VaR}$ 을 초과하 는지 사후검정(backtesting) 절차를 통해서 원-팩터 VaR 모형이 보수성을 최우선으로 하는 BIS 자기자 본규제를 위한 금융기관 내부모형으로 적합한지를 결정할 수 있다. 다만 현재 단계에서는 단지 1 일 또 는 10 일인 주식 보유기간을 적어도 1 개월 이상으로 확대하여 미래 예측되는 경기상황에 따라 선제적으 로 주가가 하락할 것으로 예상되는 업종의 주식을 처분하고 주가가 상승할 것으로 예상되는 업종의 주식 으로 포트폴리오의 자산을 재구성하여 효율적으로 손실을 최소화하는 방법으로 원-팩터 $\mathrm{VaR}$ 모형을 이 용하는 것은 충분하다. 이와 같은 원-팩터 $\mathrm{VaR}$ 모형은 각 주가의 변동성을 잘 설명할 수 있는 경기지 표를 선택하며, 또한 선택 경기지표에 대한 미래 변화를 정확하게 예측한다는 조건을 만족하는 상황에서 원-팩터 $\mathrm{VaR}$ 모형에 의해 손실을 최소화하는 효과를 기대할 수 있다. 만일 선택 경기지표에 대한 미래 변화를 잘못 예측한 경우에는 원-팩터 $\mathrm{VaR}$ 모형의 오류는 심각해질 수 있다. 전문 연구기관은 물론 금 융기관 내의 연구소에서 미래 경기지표에 대한 다양한 예측을 실시하고는 있지만, 구조적으로 미래 예측 되는 경기상황을 반영하기 위한 본 연구와는 별도로 경기지표에 대한 선택 및 예측 방법에 관한 추가적 인 연구가 요구된다.

\section{References}

Basel Committee on Banking Supervision (1995). An internal Model-Based Approach to Market Risk Capital Requirements, BIS, Basel, Switzerland.

Bessis, J. (2002). Risk Management in Banking, John Wiley \& Sons, New York.

Bollerslev, T. (1986). Generalized autoregressive conditional heteroscedasticity, Journal of Econometrics, 31, 307-327.

Engle, R. (1982). Autoregressive conditional heteroscedasticity with estimates of the variance of UK inflation, Econometrica, 50, 987-1008.

Johansson, F., Seiles, M. J. and Tjarnberg, M. (1999). Measuring downside portfolio risks, Journal of Portfolio Management, Fall, 96-107.

J. P. Morgan (1996). RiskMetrics - Technical Document, 4th edition, New York.

Neftci, S. F. (2000). Value at Risk calculations, extreme events and tail estimations, Journal of Derivatives, Spring, 23-37. 


\title{
One-factor 모형을 이용한 주식 포트폴리오 VaR에 관한 연구
}

\author{
박근희 $^{a} \cdot$ 고광이 ${ }^{a, 1}$. 백장선 ${ }^{a}$ \\ ${ }^{a}$ 전남대학교 통계학과
}

(2013년 3월 29일 접수, 2013년 6월 10일 수정, 2013년 6월 11일 채택)

요 약

J. P. Morgan의 RiskMetrics을 기반으로 하는 현행 VaR 모형은 구조적으로 미래 경기상황을 반영할 수 없는 단 점으로 인해 불안정한 경기상황에서는 손실이 $\mathrm{VaR}$ 을 초과하는 결정적인 문제점을 내포하고 있다. 어느 기업의 미 래의 주가는 해당 기업만의 고유요인은 물론 모든 기업의 주가에 공통적으로 영향을 미치는 경기변동 공통요인에 의 해 결정된다. 따라서 본 연구에서는 주가의 변동요인을 기업의 고유요인과 경기변동 공통요인으로 구분하여, 미래 경기변동 공통요인에 대해서는 현재시점에서 예측한 값을 사용하는 원-팩터(One-factor) VaR 모형을 제안한다. 이 와 같은 원-팩터 $\mathrm{VaR}$ 모형은 미래의 예측된 경기상황을 반영을 반영하여 손실이 $\mathrm{VaR}$ 을 초과하는 현행 $\mathrm{VaR}$ 모형 의 문제점을 해결할 수 있을 뿐만 아니라 자산의 목표보유기간을 증가시켜 경기변동에 따른 손실을 최소화하기 위한 포트폴리오에 대한 자산구성과 자금이전을 선제적으로 실시할 수가 있다.

주요용어: 일반화 위너확률과정, 연속복리수익률, 원-팩터 모형, $\mathrm{VaR}, \mathrm{EWMA}, \mathrm{GARCH.}$

본 논문은 2010 년도 정부(교육과학기술부)의 재원으로 한국연구재단의 지원을 받아 수행된 기초연구사업임 (No. 2010-0023279).

${ }^{1}$ 교신저자: (500-757) 광주광역시 북구 용봉로 77, 전남대학교 통계학과, 교수. E-mail: kyko0328@jnu.ac.kr 